\title{
A Pilot Study on Immunohistochemical Expressions of NF-kB, Cyclin-D1, VEGF, and Cox-2 in Advanced Stage Laryngeal Carcinoma
}

\author{
Pudji Rahaju ${ }^{1}$, Ayunita Tri Wirattami ${ }^{1}$, Ferry Sandra ${ }^{2}$, , Steffi Kurniawan ${ }^{1}$, Khairun Nisa ${ }^{1}$, \\ Soehartono $^{1}$, Edi Handoko ${ }^{1}$, Ahmad Dian Wahyudiono ${ }^{1}$, Hendradi Surjotomo ${ }^{1}$, \\ Hendy Setyo Yudhanto ${ }^{3}$, Nanik Setjowati ${ }^{4}$ \\ ${ }^{1}$ Department of Otorhinolaryngology-Head and Neck Surgery, Faculty of Medicine, Universitas Brawijaya/Dr. Saiful Anwar General Hospital, \\ Jl. Veteran, Malang, Indonesia \\ ${ }^{2}$ Department of Biochemistry and Molecular Biology, Section of Oral Biology, Faculty of Dentistry, Universitas Trisakti, Jl. Kyai Tapa No. 260, \\ Jakarta, Indonesia \\ ${ }^{3}$ Department of Anatomic Pathology, Faculty of Medicine, Universitas Brawijaya/Dr. Saiful Anwar General Hospital, Jl. Veteran, Malang, Indonesia \\ ${ }^{4}$ Department of Public Health-Prevention Medicine, Faculty of Medicine, Universitas Brawijaya, Jl. Veteran, Malang, Indonesia \\ *Corresponding author. E-mail: ferry@trisakti.ac.id
}

Received date: Apr 9, 2021; Revised date: Sep 1, 2021; Accepted date: Sep 3, 2021

\section{Abstract}

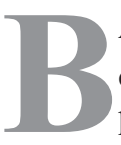

ACKGROUND: Progression of laryngeal carcinoma can be classified with the clinical staging, however there are different patterns of progressions observed in the patient with the same clinical stage which also affects their prognoses. Therefore biomarkers should be used. Nuclear factor (NF)-кB, Cyclin-D1, vascular endothelial growth factor (VEGF), cyclooxygenase (Cox)-2 have been reported for laryngeal carcinoma. However, it is still unclear how these markers are expressed and correlated in advanced stage laryngeal carcinoma. Therefore current study was conducted to investigate the expressions of NFкB, Cyclin-D1, VEGF and Cox-2 and their correlations in advanced stage laryngeal carcinoma.

METHODS: Subjects were recruited and laryngeal biopsies were collected, fixed in formalin and prepared for immunohistochemistry. The immunohistochemistry was performed using mouse monoclonal anti-NF- $\kappa \mathrm{B}$ p65, anti-Cyclin-D12 anti-VEGF, and anti-Cox-2 antibodies. The immunohistochemistry results were documented and measured using ImmunoRatio. Pearson or Spearman correlation test was used based on the results of ShapiroWilk test of normality. A $p$-value of less than 0.05 is considered statistically significant.

RESULTS: Twelve male subjects were included in this study. Expressions of NF-KB, Cyclin-D1, VEGF dan Cox2 were clearly observed. Mean of NF-KB, Cyclin-D1, VEGF dan Cox-2 IHC expression levels measured with ImmunoRatio were $57.50 \pm 20.06 \%, \quad 45.00 \pm 24.31 \%$, $43.33 \pm 17.23 \%$ and $40.42 \pm 16.98 \%$, respectively. There was significant correlation between the expressions of VEGF dan Cox-2 ( $p=0.031, \mathrm{r}=0.622)$.

CONCLUSION: Since correlation between the VEGF and Cox-2 expressions was statistically significant, VEGF and Cox-2 might have important roles in the growth, invasion and metastasis of laryngeal carcinoma.

KEYWORDS: advanced stage laryngeal carcinoma, immunohistochemistry, NF-KB, Cyclin-D1, VEGF, Cox-2

Indones Biomed J. 2021; 13(4): 350-4

\section{Introduction}

The laryngeal carcinoma is the second most common head and neck carcinoma after the nasopharyngeal carcinoma. Smoking and alcohol consumption are known as the risk factors for laryngeal carcinoma.(1) In Indonesia, the incidence of laryngeal carcinoma for men and women are 2.0 per 100,000 and 0.2 per 100,000, respectively.(2) Although progression of laryngeal carcinoma can be classified with the clinical staging, however there are different patterns of progressions observed in the patient with the same clinical 
stage which also affects their prognoses.(3) Therefore biomarkers should be used. Various factors, including hypoxia, cytokines, oncogenes, tumor suppressor genes, have been known to regulate the expression of angiogenic factor in laryngeal carcinoma. Nuclear factor (NF)- $\mathrm{kB}$ is a transcription factor which control gene expression and regulate the immune response. The activation of the NF-KB affects cancer markers and inflammatory diseases through the process of gene transcription in cell proliferation, survival, angiogenesis, inflammation, tumor promotion and metastasis.(4-6)

Cyclin-D1 plays a role in the cell cycle and cell proliferation and act as an oncogene. There are several studies that have shown a significant association between the increase in the Cyclin-D1 expression and the local tumor extension. NF-KB-mediated continuous cell proliferation can activate Cyclin-D1 via cell cycle modulation. $(7,8)$ Cyclin-dependent kinase (CdK) 4 and/or 6 are activated by Cyclin D in the early gap (G)1 phase of the cell cycle.

The other factor is the vascular endothelial growth factor (VEGF), an angiogenic factor, which has specific mitogenic activity for endothelial cells. It is the most important angiogenic factor in the angiogenesis process, both in physiological and pathological conditions.(9) The studies have shown that the overexpression of VEGF was associated with tumor progression.(9-11)

Cyclooxygenase (Cox)-2 has been suggested as a better marker for tumor promotion and metastasis. Cox-2 was identified as a metastatic factor in bone, lymph nodes, liver, brain and other organs.(12) The Cox-2 expression can be used as a predictive and prognostic marker of laryngeal squamous cell carcinoma. $(13,14)$

Although NF-kB, Cyclin-D1, VEGF and Cox-2 have been reported as important markers in laryngeal carcinoma, it is still unclear how these markers are expressed and correlated in advanced stage laryngeal carcinoma. Not enough information can be gathered, meanwhile correlations of these markers should be important to give added value for the improvement of clinical evaluation. Therefore current study was conducted to investigate the expressions of NFкB , Cyclin-D1, VEGF and Cox-2 and their correlations in advanced stage laryngeal carcinoma.

\section{Methods}

\section{Subject Recruitment and Selection}

Subjects were recruited from January 1, 2018 to June 30, 2020, in the Ear, Nose \& Throat (ENT) Clinic of Dr. Saiful
Anwar Hospital, Malang. A written Informed consent was obtained from all subjects.

The subjects' demography such as gender, age, smoking history and clinical stage were recorded. The clinical staging was determined based on the American Joint Committee of Cancer (AJCC).(15) Laryngeal biopsies of subjects with advanced stage laryngeal squamous cell carcinoma were included. However biopsies of the subjects who underwent radiotherapy or chemotherapy were excluded. This study was approved by The Ethics Committee of Faculty of Medicine, Universitas Brawijaya (No. 100/092/K.3/302/2020).

\section{Immunohistochemistry (IHC)}

Formalin-fixed and paraffin-embedded tissues were processed in the Laboratory of Anatomic Pathology, Dr. Saiful Anwar Hospital, Malang. The tissues were sliced with microtome, deparaffinized, antigen-retrieved, endogenous-peroxidase-blocked and applied with blocking solution. Mouse monoclonal anti-NF-кB p65 (sc-514451, Santa Cruz, Dallas, TX, USA), anti-Cyclin-D1 (sc-8396, Santa Cruz), anti-VEGF (sc-7269, Santa Cruz), and antiCox-2 (sc-376861, Santa Cruz) antibodies were applied as primary antibodies. Bounds of antigen-antibody were further processed with N-Histofine Simple Stain MAX PO containing polymer anti-mouse and anti-rabbit secondary antibodies, peroxidase and 3,3'-diaminobenzidine buffer (Nichirei, Tokyo, japan). The immunohistochemistry results were documented, five fields were selected for each sample, under an upright light microscope (Nikon, Tokyo, Japan). Documented results were measured using ImmunoRatio.

\section{Statistical Analysis}

Correlation analysis of NF- $\kappa \mathrm{B}$ and Cyclin-D1, VEGF and Cox-2 expression were conducted using SPSS for Windows software version 20 (IBM, Armonk, NY, USA). Pearson or Spearman correlation test was used based on the results of Shapiro-Wilk test of normality. A p-value of less than 0.05 is considered statistically significant.

\section{Results}

Twelve male subjects were included in this study. Most of the subjects were older adult (56-65 years) $(50 \%)$, had history of smoking (91.67\%), tumor size of T4 (66.67\%), nodule staging of N2 (66.7\%) and stadium of IVa (75\%) (Table 1). 
Table 1. Advanced laryngeal carcinoma subject characteristics $(\mathrm{n}=12)$.

\begin{tabular}{|c|c|c|}
\hline Characteristics & $\mathbf{n}$ & $\%$ \\
\hline \multicolumn{3}{|l|}{ Gender } \\
\hline Male & 12 & 100 \\
\hline Female & 0 & 0 \\
\hline \multicolumn{3}{|l|}{ Age Group } \\
\hline Young Adult (36-45 years) & 2 & 16.67 \\
\hline Middle Adult (46-55 years) & 1 & 8.33 \\
\hline Older Adult (56-65 years) & 6 & 50 \\
\hline Elderly (> 65 years) & 3 & 25 \\
\hline Smoking History & 11 & 91.67 \\
\hline \multicolumn{3}{|l|}{ Clinical Staging } \\
\hline \multicolumn{3}{|l|}{ Tumor } \\
\hline $\mathrm{T} 1$ & 0 & 0 \\
\hline $\mathrm{T} 2$ & 2 & 16.67 \\
\hline $\mathrm{T} 3$ & 2 & 16.67 \\
\hline $\mathrm{T} 4$ & 8 & 66.67 \\
\hline \multicolumn{3}{|l|}{ Nodule } \\
\hline No & 3 & 25 \\
\hline N1 & 0 & 0 \\
\hline $\mathrm{N} 2$ & 8 & 66.67 \\
\hline N3 & 1 & 8.33 \\
\hline \multicolumn{3}{|l|}{ Stadium } \\
\hline III & 2 & 16.67 \\
\hline IVa & 9 & 75 \\
\hline $\mathrm{IVb}$ & 1 & 8.33 \\
\hline
\end{tabular}

IHC Expressions of NF-kB, Cyclin-D1, VEGF and Cox-2

Expressions of NF-kB, Cyclin-D1, VEGF dan Cox-2 were clearly observed. Brown color in the cytoplasm was documented for NF-KB (Figure 1A). Brownish smear color in the cytoplasm was documented for VEGF dan Cox-2 (Figure 1C\&1D). Meanwhile brown color in the nucleus was documented for Cyclin-D1 (Figure 1B). Mean of NF-KB, Cyclin-D1, VEGF dan Cox-2 IHC expression levels measured with ImmunoRatio were $57.50 \pm 20.06 \%$, $45.00 \pm 24.31 \%, \quad 43.33 \pm 17.23 \% \quad$ and $\quad 40.42 \pm 16.98 \%$, respectively (Figure 1E).

\section{Correlation of NF-kB, Cyclin-D1, VEGF and Cox-2 IHC} Expressions

After being analysed with Spearman correlation test, almost all correlations between the NF-KB, Cyclin-D1,
VEGF and Cox-2 were not significant, except the correlation between VEGF dan Cox-2 $(p=0.031, \mathrm{r}=0.622)$ (Table 2).

\section{Discussion}

Current results showed that advanced stage laryngeal carcinoma had $>50 \%$ NF- $\mathrm{kB}$ expression level. This result is in accordance with previous study showing that normal tissue has $<5 \%$ NF- $\mathrm{kB}$ expression level, dysplastic tissue has $5-50 \% \mathrm{NF}-\mathrm{kB}$ expression level, and carcinoma tissue has $>50 \%$ NF- $\kappa B$ expression level.(16)

For Cyclin-D1, low expression was categorized as $\leq 25 \%$ and high expression was $>25 \%$.(17) In current results, Cyclin-D1 expression level of advanced stage laryngeal carcinoma was $45.00 \pm 24.31 \%$, suggesting a confirmation of high Cyclin-D1 expression.

For VEGF, the expressions were classified into level 0 ( $<1 \%$ positive cells), level 1 ( $>1-33 \%$ positive cells), level 2 ( $>34-66 \%$ positive cells) and level 3 ( $>67 \%$ positive cells).(17) In current results, VEGF expression level was $43.33 \pm 17.23 \%$, suggesting the advanced stage laryngeal carcinoma also had high expression of VEGF.

For Cox-2, the negative and positive cut-off was reported as $10 \%$, therefore $\leq 10 \%$ was negative while $>10 \%$ was positive.(18) In current result, the Cox2 expression level was $40.42 \pm 16.98 \%$, suggesting high expression of Cox-2 as well in the advanced stage laryngeal carcinoma.

Modulation of VEGF by prostaglandins produced by Cox-2 or induction of endothelial cells by Cox-2 can lead to tumor angiogenesis.(19) In the current results, VEGF and Cox-2 expressions of the advanced stage laryngeal carcinoma were significantly correlated $(\mathrm{r}=0.622, p=0.031)$. These results are similar with a previous report showing that a positive correlation between the VEGF and Cox-2 expressions in laryngeal squamous cell carcinoma $(\mathrm{r}=0.756$, $p<0.01)$.(20) There was a higher increase in the expression of VEGF and Cox-2 in advanced laryngeal squamous cell carcinoma (stadium 3 and 4) than early stadium (stadium 1 and 2).(21) This suggested the major role of VEGF and Cox-2 in the growth, invasion and metastasis of laryngeal carcinoma.

The limitation of available sample numbers in this study which were collected in the last 2 years should be improved, therefore advanced stage laryngeal carcinoma samples would be collected continuously for future investigation. 

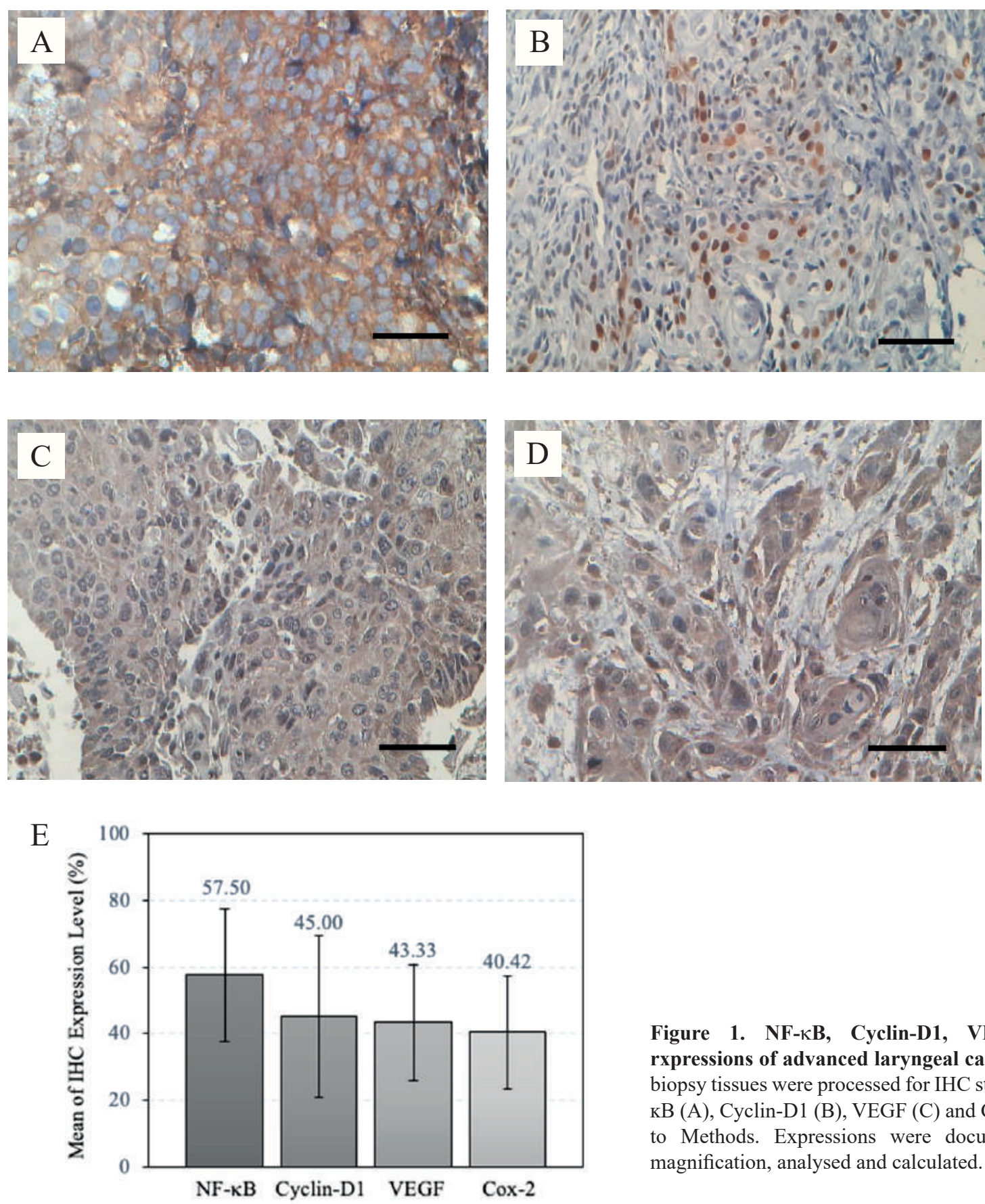

Figure 1. NF- $\kappa$ B, Cyclin-D1, VEGF, and Cox-2 rxpressions of advanced laryngeal carcinoma. Laryngeal biopsy tissues were processed for IHC staining to detect NFкB (A), Cyclin-D1 (B), VEGF (C) and Cox-2 (D) according to Methods. Expressions were documented with 400x magnification, analysed and calculated. Black bar: $10 \mu \mathrm{m}$.

Table 2. The correlation between NF-кB, Cyclin-D1, VEGF and Cox-2 IHC expressions of advanced laryngeal carcinoma.

\begin{tabular}{|c|c|c|c|c|c|c|c|c|}
\hline \multirow{2}{*}{ Biomarker } & \multicolumn{2}{|c|}{ NFKB } & \multicolumn{2}{|c|}{ Cyclin D1 } & \multicolumn{2}{|c|}{ VEGF } & \multicolumn{2}{|c|}{ Cox-2 } \\
\hline & $r$ & $p$ & $r$ & $p$ & $r$ & $p$ & $r$ & $p$ \\
\hline $\mathrm{NF} \kappa \mathrm{B}$ & - & - & -0.101 & 0.755 & 0.182 & 0.572 & -0.142 & 0.661 \\
\hline Cyclin-D1 & -0.101 & 0.755 & - & - & 0.106 & 0.743 & 0.156 & 0.628 \\
\hline VEGF & 0.182 & 0.572 & 0.106 & 0.743 & - & - & 0.622 & $0.031 *$ \\
\hline Cox-2 & -0.142 & 0.661 & 0.156 & 0.628 & 0.622 & $0.031 *$ & - & - \\
\hline
\end{tabular}




\section{Conclusion}

Since correlation between the VEGF and Cox-2 expressions was statistically significant, VEGF and Cox-2 might have important roles in the growth, invasion and metastasis of laryngeal carcinoma. Further investigation with more numbers of sample should be pursued.

\section{Acknowledgements}

This research was funded by the Research Division of Dr. Saiful Anwar Hospital, Malang. Author declare no conflict of interest related to the material presented in this article.

\section{Authors Contribution}

PR contributed in research conception and design, ATW, FS, SK, and KN performed the data acquisition and analysis, result interpretation, manuscript preparation, figure and table design. FS, HTN, EH, ADW, HS and HSY contributed in data analysis and result interpretation. FS and NS contributed in data analysis. All authors took parts in giving critical revision of the manuscript.

\section{References}

1. Kontos CK. Molecular biomarkers of prognosis in laryngeal squamous cell carcinoma. OA Cancer. 2013; 1: 12.

2. Putri S, Dewi Y, Dewayani B. Risk factors of laryngeal carcinoma in Otorhinolaryngology-Head and Neck Division of Dr. Hasan Sadikin Hospital Bandung. J Med Health. 2018; 2: 1007. doi: 10.28932/jmh. v2i2.1007.

3. Akdeniz O, Akduman D, Haksever M, Ozkarakas H, Muezzinoglu B. Relationships between clinical behavior of laryngeal squamous cell carcinomas and expression of VEGF, MMP-9 and E-Cadherin. Asian Pac J Cancer Prev. 2013; 14: 5301-10.

4. Park M, Hong J. Roles of NF- $\mathrm{kB}$ in cancer and inflammatory diseases and their therapeutic approaches. Cells. 2016; 5: 15. doi: 10.3390/ cells5020015.

5. Sandra F, Kukita T, Tang QY, Iijima T. Caffeic acid inhibits NFkappaB activation of osteoclastogenesis signaling pathway. Indones Biomed J. 2011; 3: 216-22.

6. Hendarmin L, Kawano S, Yoshiga D, Sandra F, Mitsuyasu T, Nakao $\mathrm{Y}$, et al. An anti-apoptotic role of NF- $\mathrm{BB}$ in TNF $\alpha$-induced apoptosis in an ameloblastoma cell line. Oral Sci Int. 2008; 5: 96-103.
7. Rahaju P, Kintono R, Wahyudiono A, Satria A, Sandra F. Immunohistochemical expression of EGFR, NF-kB and Cyclin D1 in sinonasal inverted papilloma and squamous cell carcinoma. Indones Biomed J. 2020; 12: 239-44.

8. John RR, Malathi N, Ravindran C, Anandan S. Mini review: Multifaceted role played by cyclin D1 in tumor behavior. Indian J Dent Res. 2017; 28: 187-92.

9. Lukito B, Suriapranata I, Pendrianto P, Sulaiman A, Yusuf I, Suhadi $\mathrm{FXB}$, et al. Vascular endothelial growth factor level as a predictor of hepatocellular carcinoma in liver cirrhosis patients. Indones Biomed J. 2014; 6: 167-74.

10. Akdeniz O, Akduman D, Haksever M, Ozkarakas H, Muezzinoglu B. Relationships between clinical behavior of laryngeal squamous cell carcinomas and expression of VEGF, MMP-9 and E-Cadherin. Asian Pac J Cancer Prev. 2013; 14: 5301-10.

11. Hoeben A, Landuyt B, Highley M, Wildiers H, Van Oosterom A, De Bruijn E. Vascular endothelial growth factor and angiogenesis. Pharmacological Rev. 2004; 56: 549-80.

12. Hashemi G, Najafi M, Salehi E, Farhood B, Mortezaee K. Cyclooxygenase-2 in cancer: A review. J Cell Physiol. 2018; 234: 5683-99.

13. Iype E, Balakrishna R, Subhadradevi L, Vinoda Thulaseedharan J, Singh R, Jayasree K. Cyclooxygenase-2 expression in squamous cell carcinoma of larynx: association with clinico-pathological factors and treatment outcomes. Int J Otorhinolaryngol Head Neck Surg. 2021; 4: 970-6.

14. Yang B, Jia L, Guo Q, Ren H, Hu Y, Xie T. Clinicopathological and prognostic significance of cyclooxygenase-2 expression in head and neck cancer: a meta-analysis. Oncotarget. 2016; 7: 47265-77.

15. Edge S, Byrd D, Compton C, Fritz A, Greene F, Trotti A. AJCC Cancer Staging Manual, Larynx Staging Form. 8th ed. New York: Springer; 2017.

16. Abbas NF, El-Sharkawy SL, Abbas EA, El-Shaer MAM. Immunohistochemical study of p53 and angiogenesis in benign and preneoplastic oral lesions and oral squamous cell carcinoma. Oral Surg Oral Med Oral Pathol Oral Radiol. 2007; 103: 385-90.

17. Dong Y, Sui L, Sugimoto K, Tai Y, Tokuda M. Cyclin D1-CDK4 complex, a possible critical factor for cell proliferation and prognosis in laryngeal squamous cell carcinomas. Int $\mathrm{J}$ Cancer. 2001; 95: 209-15.

18. Chen Z, Yan B, Van Waes C. Role of the NF- $\kappa B$ transcriptome and proteome as biomarkers in human head and neck squamous cell carcinomas. Biomarker Med. 2008; 2: 409-26.

19. Gunantara I, Dewi I, Artha I. Ekspresi vascular endothelial growth factor berhubungan positif dengan kedalaman invasi pada adenokarsinoma kolorektal. Majalah Patologi Indones. 2019; 28: 44-9.

20. Guangli C, Yingpeng L, Jianting W, Linghui L, Pei C, Juan D, et al. Expression of vascular endothelial growth factor and cyclooxygenase-2 in laryngeal squamous cell carcinoma and its significance. J Huazhong Univ Sci Technol. 2006; 26: 105-7.

21. Yuan A, Yu C, Shun C, Luh K, Kuo S, Lee YC, et al. Total cyclooxygenase-2 mRNA levels correlate with vascular endothelial growth factor mRNA levels, tumor angiogenesis and prognosis in non-small cell lung cancer patients. Int J Cancer. 2005; 115: 545-55. 